\title{
Modal Gain Characteristics of A Two-section InGaAs/GaAs Double Quantum Well Passively Mode-locked Laser with Asymmetric Waveguide
}

Qiao Zhongliang ( $\sim$ qzhl060910@hainnu.edu.cn )

Hainan Normal University

\section{Xiang Li}

Temasek Laboratories@NTU (TL@NTU), Nanyang Technological University

\section{Brian Sia}

Nanyang Technological University

\section{Wanjun Wang}

Nanyang Technological University

\section{Hong Wang}

Temasek Laboratories@NTU (TL@NTU), Nanyang Technological University

\section{Zaijin Li}

Hainan Normal University

\section{Zhibin Zhao}

Hainan Normal University

Lin Li

Hainan Normal University

\section{Xin Gao}

Changchun University of Science and Technology

\section{Baoxue Bo}

Changchun University of Science and Technology

\section{Yi Qu}

Hainan Normal University

\section{Guojin Liu}

Hainan Normal University

\section{Liu Chongyang}

Temasek Laboratories@NTU (TL@NTU), Nanyang Technological University

\section{Research Article}

Keywords: Passively mode-locked lasers, Asymmetric waveguide, Modal gain characteristics, Hakki-Paoli method, Gain peak 
Posted Date: September 1st, 2021

DOl: https://doi.org/10.21203/rs.3.rs-847211/v1

License: (c) (i) This work is licensed under a Creative Commons Attribution 4.0 International License. Read Full License 


\section{Abstract}

Monolithic two-section InGaAs/GaAs double quantum well (DQW) passively mode-locked lasers (MLLs) with asymmetric waveguide, concluding the layers of P-doped AlGaAs waveguide and no-doped InGaAsP waveguide, emitting at $\sim 1.06 \mu \mathrm{m}$, with a fundamental repetition rate at $\sim 19.56 \mathrm{GHz}$ have been demonstrated. Modal gain characteristics, such as a gain bandwidth and a gain peak wavelength of the $M L L$, as a function of the saturable absorber (SA) bias voltage $\left(V_{a}\right)$ as well as the injection current of gain section $\left(I_{g}\right)$, were investigated by the Hakki-Paoli method. With the increase of $V_{a}$, the lasing wavelength and net modal gain peak of the MLL both exhibited red-shifts to longer wavelength significantly, while the modal gain bandwidth was compressed. Both the net modal gain bandwidth and gain peak of the MLL followed a polynomial distribution versus the reverse bias at the absorber section. In addition, for the first time, it was found that $V_{a}$ had an obvious effect on the differential gain of the MLL.

\section{Introduction}

Monolithic semiconductor passively mode-locked lasers (MLLs) are ideal light sources for short optical pulses, and particularly attractive for their low cost, small size and ease of pumping. In recent years, light sources emitting at $1.06 \mu \mathrm{m}$, with an ultra-short pulse, have attracted great research interests, which are promising for many applications such as biometric imaging [1, 2], frequency comb[3], two-photon microscopy (TPM) [4], lidar remote sensing [5, 6], and so on. In addition, they are also used as pump sources $[7,8]$. These are of particular interest given their substantial impact on the applications in photonics and system integration.

Multi-section waveguide structure is generally adopted in a semiconductor mode-locked laser [9-12], where the gain section is forward biased and saturable absorber (SA) section is reversely biased. The gain properties of single-section InGaAs/GaAs QW/QD lasers also have been intensively studied [9-14]. DQW MLLs have higher output power and Electro-optic conversion efficiency than QD MLLs, and multisection DQW MLLs also can generate shorter pulse [15]. However, the modal gain characteristics, i.e., modal gain bandwidth, peak, of multi-section InGaAs/GaAs DQW MLLs remains unexplored. All these have an important impact on the application of MLLs. Furthermore, as we all know that the thermal stability of InGaAsP semiconductor laser is better than that of AlGaAs[16], P-doped AIGaAs is easier to achieve high-quality growth than p-doped InGaAsP materials, and the ultrafast carrier dynamics in InGaAsP is better than that in AlGaAs, these characteristics of which is more suitable for generating shorter light pulses in an electrically pumped edge emitting semiconductor MLL.

So we report and demonstrate a monolithic two-section passive DQW MLL with asymmetric waveguide emitting at $1.06 \mu \mathrm{m}$ getting shorter pulse width and high output power, and the modal gain characteristics is investigated by the Hakki-Paoli method[17-21] to get better understanding on its bias-dependent output. The layers of P-doped AIGaAs waveguide and no-doped InGaAsP waveguide are included in the asymmetric waveguide. For the first time to our knowledge, picosecond pulse generation was achieved by a two-section InGaAs/GaAs DQW MLL with asymmetric waveguide emitting at $\sim 1.06 \mu \mathrm{m}$ without 
external pulse compression, and the radio frequency (RF) spectrum, dynamic spectrum, net modal gain, and photocuurent performances on the absorber are systematically analyzed for two-section InGaAs/GaAs DQW MLLs. The pulse width and the peak power are also measured for the prepared monolithic two-section MLL.

\section{Device Overview And Experimental Setup A. Material Structure}

In this work, 1.06- $\mu \mathrm{m}$ InGaAs/GaAs DQW laser structures, with asymmetric waveguide, were grown on nGaAs(100) substrates by metalorganic chemical vapor deposition (MOCVD). The detailed epitaxial structure is shown in the Table I, similar to our previous study [22].

TABLE I.1.06- $\mu \mathrm{m}$ InGaAs DQW laser with asymmetric heterostructure layers

\begin{tabular}{|c|c|c|}
\hline Material & Thickness (nm) & Doping $\left(\mathrm{cm}^{-3}\right)$ \\
\hline GaAs & 250 & 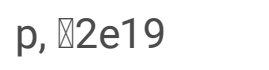 \\
\hline $\mathrm{Al}_{0.55} \mathrm{Ga}_{0.45} \mathrm{As}$ & 300 & p, $6 \mathrm{e} 18$ \\
\hline $\mathrm{Al}_{0.35} \mathrm{Ga}_{0.65} \mathrm{As}$ & 300 & $\mathrm{p}, 8 \mathrm{e} 17$ \\
\hline $\mathrm{Al}_{0.3} \mathrm{Ga}_{0.7} \mathrm{As}$ & 300 & $\mathrm{p}, 8 \mathrm{e} 17$ \\
\hline $\mathrm{Al}_{0.05} \mathrm{Ga}_{0.95} \mathrm{As}$ & 200 & p, $8 \mathrm{e} 16$ \\
\hline GaAs & 8 & barrier \\
\hline $\mathrm{In}_{0.2} \mathrm{Ga}_{0.8} \mathrm{As}$ & 7 & quantum well \\
\hline GaAs & 8 & barrier \\
\hline $\mathrm{In}_{0.2} \mathrm{Ga}_{0.8} \mathrm{As}$ & 7 & quantum well \\
\hline GaAs & 8 & barrier \\
\hline $\operatorname{In}_{0.03} \mathrm{Ga}_{0.97} \mathrm{As}_{0.95} \mathrm{P}_{0.05}$ & 200 & non-doped \\
\hline $\mathrm{In}_{0.32} \mathrm{Ga}_{0.68} \mathrm{As}_{0.4} \mathrm{P}_{0.6}$ & 300 & $\mathrm{n}, 8 \mathrm{e} 16$ \\
\hline $\mathrm{In}_{1-\mathrm{x}} \mathrm{Ga}_{\mathrm{x}} \mathrm{As}_{0.5} \mathrm{P}_{0.5}$ & 100 & $\mathrm{n}, 8 \mathrm{e} 17$ \\
\hline $\mathrm{In}_{1-\mathrm{x}} \mathrm{Ga}_{\mathrm{x}} \mathrm{As}_{0.7} \mathrm{P}_{0.3}$ & 100 & $\mathrm{n}, 8 \mathrm{e} 17$ \\
\hline $\mathrm{In}_{1-\mathrm{x}} \mathrm{Ga}_{\mathrm{x}} \mathrm{As}_{0.9} \mathrm{P}_{0.1}$ & 800 & $\mathrm{n}, 8 \mathrm{e} 17$ \\
\hline GaAs & 200 & $\mathrm{n}, 2 \mathrm{e} 18$ \\
\hline
\end{tabular}




\section{B. Device structure and manufacturing process}

The MLL fabrication process is similar to those reported in Refs [23, 24]. First, a $6 \mu \mathrm{m}$-wide and $1.3 \mu \mathrm{m}$ deep ridge waveguide was formed by standard lithography and wet etching. A 300-nm-thick $\mathrm{SiO}_{2}$ film was deposited as an electrical isolation layer, and a $3 \mu \mathrm{m}$-wide $\mathrm{p}$-type electrode window was opened on the etched ridge less than $6 \mu \mathrm{m}$-wide (due to the ridge etch). Then, a $10 \mu \mathrm{m}$-wide electrical isolation region was patterned by another lithography step. Ti/Au layers were evaporated to form the p-side ohmic contact. After that, lift-off process was carried out to expose the electrical isolation region, and a consequent wet etching process was used to improve the electrical isolation effect. An isolation resistance of $\sim 1 \mathrm{~kW}$ was achieved between the two sections. Finally, the substrate was thinned, $\mathrm{Ni} / \mathrm{Ge} / \mathrm{Au} / \mathrm{Ni} / \mathrm{Au}$ layers were evaporated on the $\mathrm{n}$-side, and then an ohmic contact layer was formed after $410{ }^{\circ} \mathrm{C}$ annealing. The processed wafer was cleaved into laser chips for device characterization. During the characterization, a thermo-electrical cooler (TEC) was used to control the operation temperature for the non-soldered MLL. In this study, the MLL was tested p-side up on the TEC, the length of the gain section $\left(L_{g}\right)$ and the saturable absorber $(\mathrm{SA})$ section $\left(L_{a}\right)$ are $1576 \mu \mathrm{m}$ and $404 \mu \mathrm{m}$, respectively. The gain section is forward driven by current $\left(I_{\mathrm{g}}\right)$ while the absorber section is reversely biased with $V_{\mathrm{a}}$. The side view of the two-section MLL with gain section and SA section is shown in Fig. 1. No coating on the cavity facet of MLLs was prepared.

\section{Measurement setup}

The reverse bias voltage is directly applied to the saturation absorption section by Keithley 2520 power supply, and the photocurrent value is automatically read.

The output light from the gain section facet was first coupled into a single mode fiber, then was split by a 10:90 fiber coupler, the 10 percent was guided into an optical spectrum analyzer (OSA, AQ6370C), and the 90 percent was further split into two equal parts: one was fed into a high-speed photodiode (PD) detector monitored by a 30-GHz real-time oscilloscope (DS093004L); another was fed as the signal source for an electrical spectrum analyzer (ESA, N9030A). The details are shown in the Fig.2.

\section{Experimental results and analysis}

The measurement sensitivity is set constant for all measurements. For the tested laser in this study, the wet etched ridge width provides single spatial mode operation condition while operating in the mode locking regime. Figure 3 shows the light output power characteristics under different reverse bias voltages of the absorber section for the tested device in the continuous wave (CW) operation at room temperature (RT). The bias voltage $\left(V_{a}\right)$ applied to the absorber section varied from $+1 \mathrm{~V}$ to $-3 \mathrm{~V}$, with a $1 \mathrm{~V}$ 
step, and $I_{\mathrm{g}}$ increased from 0 to $200 \mathrm{~mA}$ under each $V_{\mathrm{a}}$. The use of long absorber sections (up to $20.4 \%$ of total length) resulted in increased absorption and was beneficial to mode locking and obtain ultrashort pulse. As the negative bias on the absorption region increases, the threshold current changes obviously differently in two intervals, one is the interval from +1 to $-1 \mathrm{~V}$, where the threshold current increases slowly; the other is the interval from -1 to $-3 \mathrm{~V}$, the threshold current increases rapidly with increased negative bias. This phenomenon should be caused by the strong absorption of the absorption section under a strong negative bias $V_{\mathrm{a}}$. The L-I and V-I curves show the good operating characteristics of the MLL.

Stable mode locking was achieved over a wide range of $V_{a}$ (from 0 to -3V). The RF spectra were measured at $I_{\mathrm{g}}=180 \mathrm{~mA}$ and $V_{\mathrm{a}}=-0.9 \mathrm{~V}$ as shown in Fig. 4(a) using a resolution bandwidth (RBW) of 10 $\mathrm{kHz}$.. The fundamental repetition rate with more than $42 \mathrm{~dB}$ signal to noise ratio (SNR) at room temperature is $\sim 19.56 \mathrm{GHz}$, corresponding to the photon round-trip time in the $1.99 \mathrm{~mm}$-long laser cavity. The second harmonic frequency at $\sim 39.12 \mathrm{GHz}$ is also marked in the figure with $\sim 15 \mathrm{~dB}$ SNR, which indicate an efficient mode locking. The RF signal from the photodetector was also fed into a $30 \mathrm{GHz}$ realtime oscilloscope (DS093004L). Fig. 4(b) shows the pulse train observed on the oscilloscope. The time interval between two pulses is $\sim 50.78 \mathrm{ps}$, corresponding well to a repetition rate at $\sim 19.69 \mathrm{GHz}$, which is very close to the fundamental repetition rate $\sim 19.56 \mathrm{GHz}$. The response resolution of the real-time oscilloscope in picosecond and femtosecond level is not enough. Therefore, the measured time pulse train is actually an envelope of ultra-narrow pulses. It can also be seen from Fig. 4(b) that the distribution of the time-domain pulse train presents a more uniform and regular time distribution and the cycle time change is very small and barely noticeable, which shows that the time-domain pulse envelope is much closer to no chirp. It also proves that it is weakly affected by the chirp effect during the test. This provides a basis for calculating its ultra-narrow pulse width using the ideal $\operatorname{sech}^{2}$ shaped of the time-bandwidth product (TBP) later.

The full width at half maximum (FWHM) of the emission spectrum (D/) is $\sim 1.08 \mathrm{~nm}$, and the optical spectrum of the laser is centered at $1065.35 \mathrm{~nm}$. The tested peak and fitted peak curves are showed in Fig. 5. The ideal Lorentz-shaped TBP of $\sim 0.22$ is a smaller value than the ideal $\operatorname{sech}^{2}$ shaped pulses TBP of $\sim 0.315$. Here, taking into account that it is not significantly affected by the chirp, and assuming an ideal Fourier transform-limited pulse, a pulse width (PW) of $\sim 1.1 \mathrm{ps}$ can be expected by the $\mathrm{sech}^{2}$ shaped. Under this condition, the average power from the MLL is $\sim 71 \mathrm{~mW}$, corresponding to a peak power $\sim 3.3 \mathrm{~W}$. To our knowledge, this is the narrowest pulse width and the highest peak output power obtained from an electrically pumped edge emitting GaAs-based two-section semiconductor DQW-MLL.It can be seen that pulses get broadened with increasing $I_{\mathrm{g}}$, and narrowed with increasing $V_{\mathrm{a}}$.

Figure 6 shows the electroluminescence spectrum measured at different $V_{\mathrm{a}}\left(\mathrm{a}: V_{\mathrm{a}}=+1 \mathrm{~V} ; \mathrm{b}: V_{a}=0 \mathrm{~V}\right.$; c: $V_{a}=-1 \mathrm{~V} ; \mathrm{d}: V_{a}=-2 \mathrm{~V}$; e: $\left.V_{a}=-3 \mathrm{~V}\right)$. It can be found that the redshift of the lasing peak occurred is moved further away from the center of the spontaneous emission spectrum with an increasing reverse bias. As the reverse bias $V_{\mathrm{a}}$ increases, the band-gap of the absorption region shrinks significantly due to the 
quantum confined Stark effect (QCSE). In the gain spectrum of the MLL, lasing tends to happen at long wavelength while mode gain reaches the threshold current [24].

The peak is shifted from 1063 to $1074 \mathrm{~nm}$ near the threshold current under different $V_{\mathrm{a}}$. The peaks redshift, and become narrower and higher with $I_{\mathrm{g}}$ under increasing bias $V_{\mathrm{a}}$ in Fig6.(a-e) . Especially, it is also found that lasing peak will be getting obviously narrower as reverse bias changes from +1 to $-3 \mathrm{~V}$. This should be caused by the more bandgap shrinkage under big reverse bias.

Gain can be determined by amplified spontaneous emission (ASE) spectrum measurement. The net modal gain $\left(G_{\text {net }}\right)$ of the two-section MLL was computed using the Hakki-Paoli method. Fig.7 shows the net modal gain spectra at different $I_{\mathrm{g}}$ when $V_{\mathrm{a}}$ was set at $+1,0,-1,-2$ and $-3 \mathrm{~V}$, respectively. The net modal gain is extracted from the peak to valley ratio of sub-threshold Fabry-Perot oscillations, which was computed using the following relation [25].

$$
G_{n e t}(\lambda)=\Gamma g_{m}(\lambda)-\alpha_{i}=\frac{1}{L} \ln \frac{\sqrt{S(\lambda)}-1}{\sqrt{S(\lambda)}+1}+\frac{1}{2 L} \ln \left(\frac{1}{R_{1} R_{2}}\right)
$$

where $\Gamma$ is the confinement factor, $g_{\mathrm{m}}$ is the material gain, $a_{\mathrm{i}}$ is the internal loss related to defects and dopants in the waveguide and QW. $S$ is the peak-to-valley ratio of the FP resonances which can be directly obtained from the ASE spectra, $L$ is the whole cavity length $(\sim 1.99 \mathrm{~mm})$, and $R_{1}, R_{2}$ are facet reflectivity (A value of 0.346 is used for both cleaved facets). The ASE spectra were recorded with a wavelength step size of $0.02 \mathrm{~nm}$. From Fig. 7, it can be seen that, the net modal gain increases with increasing current, and reaches a value close to the mirror loss $\left(\mathrm{a}_{\mathrm{m}}=(1 / 2 L) \ln \left(1 / R_{1} R_{2}\right)=\sim 5.33 \mathrm{~cm}^{-1}\right)$, which is the threshold loss.

In the following, a comparison of ASE and gain spectra for InGaAs/GaAs DQW MLLs is implemented. Fig.7 plots the modal gain spectrum as a function of gain section currents, which is derived from the ASE spectra as shown in Fig.6, and it also shows the lasing spectrum near threshold. The laser lases exactly at wavelength of the net modal gain peak, and same results are observed at other $V_{a}$, including an internal loss, $a_{i=} \sim(1.56 \pm 0.34) \mathrm{cm}^{-1}$. An obvious redshift in the gain peak is also observed with increasing $V_{\mathrm{a}}$, which is attributed to carrier thermalisation within the DQW active layer. It can be seen that the distribution of net modal gain curve tends to be closer near the threshold current at a larger negative $V_{a}$ value. From formula (1), a larger negative $V_{a}$ causes the first item on the right side of the formula to become closer to zero, which means the value of $S$ approaching to $+¥$.When $S$ value is getting larger, the modes of the MLL becomes more stable, also exhibiting a higher power output.

Figure. 8 shows the peak net modal gain as a function of gain section injection current at $+1,0,-1,-2$ and $-3 \mathrm{~V}$ bias voltage, respectively, all measured just at or below the threshold. With increasing reverse bias voltage, the peak net modal gain decreases at constant gain current, which is similarly reported It revealed that the dissociation time of the exciton (the width of exciton absorption peak) in the saturable absorber determines the pulse width of mode locked laser. The exciton binding energy of is higher for $\ln P$ 
system and is lower for GaAs/AlGaAs than that for InGaAs/GaAs. The exciton absorption peak shift toward the longer wavelength as the reverse bias is applied (QCSE effect). On the other hand, the gain peak will shift slightly toward shorter wavelength due to band filling effect as the cavity loss increases with reverse bias to the SA section. As a result, the gain peak and absorption peak are separated (as Refs $[26,27]$. also observed). Therefore, in this paper, the bandgap of SA was shifted to the shorter wavelength to match the gain and the absorption peaks. This helps to generate short pulse for mode-locked lasers.

for the QD lasers $[28,29]$. Peak gain saturation trend is observed under a high bias voltage at room temperature, while the temperature condition in the reference is at $80^{\circ} \mathrm{C}$. The slope of peak net modal gain versus current declines obviously with reverse bias voltage increasing, which may be caused by the increased the thermal effect of photocurrent in the absorber. This will be further discussed in the following part.

In Fig. 9, the net modal gain spectra at threshold for the same sample at different $V_{\text {a }}$ are plotted. The linear fitting is usually used to derive the internal loss $\left(a_{\mathrm{i}}\right)$, which relies on the assumption that the internal differential efficiency keeps constant for lasers with different cavity length. The modal internal loss $\left(a_{i}\right)$ of the DQW laser is derived to be $(1.56 \pm 0.34) \mathrm{cm}^{-1}$, which is a higher value than the data reported previously [30]. The high internal loss should be caused by the significant shrinking of band gap of the saturated absorption region under negative $V_{\mathrm{a}}$. The $V_{\mathrm{a}}$-dependent net modal gain spectra from +1 to $-3 \mathrm{~V}$, are measured near threshold current. It can also be seen from Fig 9 that the gain peak is red-shifted and the gain bandwidth is narrowed. These factors lead to an increase in internal optical loss. This is consistent with the internal loss result of the test.

The net modal gain peak redshifts consistently about $10 \mathrm{~nm}$ with increasing negative $V_{\mathrm{a}}$, which may be mainly due to the absorption spectrum shift by the quantum well band-gap shrinking effect. Since the lasing start exactly at the location of the net modal gain peak of the MLL, it also implies a potential application for wavelength tunable or multi-wavelength laser [31]. Both of the polynomial fitting curves imply a very good adjustability. As expected, at all absorber biases, the peak value of net modal gain has nearly a similar value which is mainly determined by mirror loss.

Figure 10 shows the photocurrent $\left(I_{\mathrm{s}}\right)$ at absorption region increases as $I_{\mathrm{g}}$ increases, and increases with the $V_{a}$ negatively increasing. $I_{s}$ comes from the saturated absorption region under reverse bias, and its current direction and magnitude are related to the applied bias. When $I_{\mathrm{g}}>140 \mathrm{~mA}$, $I_{\mathrm{s}}$ saturates in the reverse bias voltage range of -3 to $-2 \mathrm{~V}$. Comparing the effect of $I_{\mathrm{g}}$ on photocurrent, a higher $I_{\mathrm{g}}$ has much greater influence on the photocurrent of MLL, while $V_{\mathrm{a}}$ has important effect on photocurrent saturation. For example, when $V_{\mathrm{a}}$ is in the range of -3 to $-2 \mathrm{~V}, I_{\mathrm{s}}$ increases with $V_{\mathrm{a}}$ negatively increasing, and then saturates. Especially, in Fig.10, the increment of $I_{s}$ versus gain current $\left(I_{g}\right)$ is uneven under $-2 \mathrm{~V}$ bias. And the efficiency that gain current converts photon into photocurrent gets to the highest value from 120 to $140 \mathrm{~mA}$ under $-2 \mathrm{~V}$ reverse bias, which indicates the most photons are absorbed by the absorption section. 
So mode-locking always happen at high photon absorption status of the absorber, such as $V_{\mathrm{a}}=-0.9 \mathrm{~V}$ while $I_{\mathrm{g}}=180 \mathrm{~mA}$, as shown in Fig. 4(a).

\section{Conclusion}

A monolithic two-section InGaAs/GaAs DQW MLL with asymmetric waveguide emitting at $\sim 1.06 \mu \mathrm{m}$ is demonstrated, and its mode-locking characteristics have been investigated. The mechanisms of the operating behavior are analyzed based on the gain and the saturable absorption in the device.

The fundamental repetition rate with more than $42 \mathrm{~dB}$ signal to noise ratio (SNR) is measured at $\sim 19.56$ $\mathrm{GHz}$, and an ultra-short pulse width (PW) of $1.1 \mathrm{ps}$ is achieved with a peak power of $\sim 3.3 \mathrm{~W}$. These results are generally better than the reported by most traditional electrically pumped edge emitting semiconductor MLL. The spectral width and peaks are measured, which become narrower and higher as the bias $V_{\mathrm{a}}$ is negative increased, and the MLLis redshifted while operating in the above changing. The gain peak redshift is observed with increasing $V_{a}$, which may be attributed to carrier and photocurrent thermalisation in the DQW active layer. The net modal gain spectrum of MLL with InGaAs DQW has been measured under different bias $V_{\mathrm{a}}$ and at gain region current $I_{\mathrm{g}}$. An internal loss of $(1.56 \pm 0.34) \mathrm{cm}^{-1}$ is achieved. It also is found that the photocurrent tends to saturate under high reverse bias voltage. And the PW and peak power can still be further optimized by the multi-section or other structure designs of MLL.

Overall, the results show monolithic two-section InGaAs/GaAs DQW MLL with asymmetric waveguide is more suitable for generating shorter light pulses, and there are of great significance to the research of ultrafast semiconductor mode-locked lasers.

\section{Declarations}

Acknowledgments

The authors would like to thank for supported in part by Hainan Province Key R\&D Program Project(ZDYF2020036) खNational Natural Science Foundation of China (Nos.61964007/61774024/61864002), National Research Foundation of Singapore (NRF-CRP12-201304), Hainan Provincial Natural Science Foundation of China (No.2018CXTD336), National Key R\&D Project (No.2017 YFB0405100), Jilin province science and technology development plan(20190302007GX)

Author Contributions Statement

Qiao Zhongliang wrote the main manuscript. All authors reviewed the manuscript.

\section{References}


1. Marschall, S. et al. \&P. E. Andersen. Broadband Fourier domain mode-locked laser for optical coherence tomography at $1060 \mathrm{~nm}$. Proc. SPIE 8213, Optical Coherence Tomography and Coherence Domain Optical Methods in Biomedicine XVI, 82130R(2012).

2. Chen, Y. L., Burnes, D. L., De Bruin, M., Mujat, M. \& De Boer, J. F. Three-dimensional pointwise comparison of human retinal optical property at 845 and $1060 \mathrm{~nm}$ using optical frequency domain imaging. J. Bio. Opt, 14 (2), 024016 (2009).

3. Guy Millot, S. Ã., Pitois, M., Hovhannisyan, Y. T., Bendahmane, A. \& Hänsch, T. W. \& Nathalie Picqué. Frequency-agile dual-comb spectroscopy. Nature Photon, 10, 27-30 (2015).

4. Kusama, Y. et al. \& H. Yokoyama. 7-ps optical pulse generation from a 1064-nm gain-switched laser diode and its application for two-photon microscopy. Opt. Express, 22 (5), 5746-5753 (2014).

5. Herrman, E., Smowton, P. M., Summers, H. D. \& Thomson, J. D. \& M.Hopkinson. Modal gain and internal optical mode loss of a quantum dot laser. Appl. Phys. Lett, 77, 163 (2000).

6. Smowton, P. M., Herrmann, E., Ning, Y., Summers, H. D. \& Blood, P. Optical mode loss and gain of multiple-layer quantum-dot lasers. Appl. Phys. Lett, 78, 2629 (2001).

7. Hu, M. H. et al. High-power high-modulation-speed 1060-nm DBR lasers for green-light emission. IEEE Photonics Technol. Lett, 18 (4), 616 (2006).

8. Nguyen, H. K. et al. \&C. Zah. Reliable high-power 1060 nm DBR lasers for second-harmonic generation. Electron. Lett, 43 (13), 716 (2007).

9. Klehr, A. et al. \& G. Tr"ankle. Second harmonic pico-second pulse generation with mode-locked 1064nm DBR laser diodes. Proc. SPIE, vol. 9002, pp. 90020F-90020F-10(2014).

10. Weber, C. et al. Picosecond pulse amplification up to a peak power of $42 \mathrm{~W}$ by a quantum-dot tapered optical amplifier and a mode-locked laser emitting at $1.26 \mu \mathrm{m}$. Opt. Lett, 40 (no. 3), 395-398 (2015).

11. Tandoi, G., Ironside, C. N. \& Marsh, J. H. \& A. C. Bryce,.Output power limitations and improvements in passively mode locked GaAs/AIGaAs quantum well lasers. IEEE J. Quantum. Electron, 48 (no. 3), 318-327 (2012).

12. Merghem, K. et al. Short pulse generation using a passively mode locked single InGaAsP/InP quantum well laser. Opt. Express, 16 (no. 14), 10675-10683 (2008).

13. Sumpf, B. et al. High-power $980 \mathrm{~nm}$ quantum dot broad area lasers. Electron. Lett, 39, 1655 (2003).

14. Kondratko, P. K., Chuang, S. L., Walter, G., Chung, T. \& Holonyak, N. Observations of near-zero linewidth enhancement factor in a quantum-well coupled quantum-dot laser. Appl. Phys. Lett, 83, 4818 (2003).

15. Weber, C., Klehr, A., Knigge, A. \& Breuer, S. Picosecond pulse generation and pulse train stability of a monolithic passively mode-locked semiconductor quantum-well laser at $1070 \mathrm{~nm}$. IEEE Journal of Quantum Electronics, 54 (3), 1-9 (2015).

16. Li, Z. M. \& Bradford, T. A Comparative Study of Temperature Sensitivity of InGaAsP and AlGaAs MQW Lasers Using Numerical Simulations. IEEE Journal of Quantum Electronics, 31 (10), 18411847 (1995). 
17. Li, X. et al. \& Chongyang Liu. Modal gain characteristics of a $2 \mu \mathrm{m} \ln \mathrm{GaSb} / \mathrm{AlGaAsSb}$ passively mode-locked quantum well laser. Appl. Phys. Lett, 111, 251105 (2017).

18. Shahid, H. et al. \& R. Murray. Gain spectrum measurement using the segmented contact method with anintegrated optical amplifier. J. Appl. Phys, 115, 163105 (2014).

19. Hakki, B. W. \& Paoli, T. L. Gain spectra in GaAs double - heterostructure injection lasers. J. Appl. Phys, 46, 1299 (1975).

20. Arsenijevic, D., Liu, C., Payusov, A., Stubenrauch, M. \& Bimberg, D. Temperature-Dependent Characteristics of Single-Mode InAs Submonolayer Quantum-Dot Lasers. IEEE Photon. Technol. Lett, 24, 906 (2012).

21. Knop, W., Harder, C. \& Bachtold, W. Compound cavity gain of tandem-electrode multiple-quantum-well AlGaAs laser diodes. IEEE Photonics Technol. Lett, 6, 338 (1994).

22. Qiao, Z. L. et al. \&H. Wang. Monolithic fabrication of InGaAs/GaAs/AlGaAs multiple wavelength quantum well laser diodes via impurity-free vacancy disordering quantum well intermixing. IEEE $J$. Electron. Devi, 5 (2), 122-127 (2017).

23. $\mathrm{Li}, \mathrm{X}$. et al. Design and analysis of $2-\mu \mathrm{m} \ln \mathrm{GaSb} / \mathrm{GaSb}$ quantum well Lasers integrated onto Siliconon-Insulator (SOI) waveguide circuits through an Al203 bonding layer. IEEE J. Sel. Top. Quantum Electron, 22 (6), 1500507 (2016).

24. Li, X. et al. \& C. Y. Liu. Modal gain characteristics of a $2 \mu \mathrm{m}$ InGaSb/AlGaAsSb passively modelocked quantum well laser. Appl. Phys. Lett, 111 (25), 1105 (2017).

25. Hakki, B. W. \& Paoli, T. L. Gain spectra in GaAs double-heterostructure injection lasers. J. Appl. Phys, 46, 1299-1305 (1975).

26. Kunimatsu, D. et al. Passively mode-locked laser diodes with bandgap-wavelength detuned saturable absorbers. IEEE Photonics Technology Letters, 11(11), Pp: 1363-1365(1999).

27. Giuseppe Tandoi, J., Javaloyes, E., Avrutin, C. N., Ironside \& John, H. Marsh. Subpicosecond Colliding Pulse Mode Locking at $126 \mathrm{GHz}$ in Monolithic GaAs/AIGaAs Quantum Well Lasers: Experiments and Theory. IEEE J. Sel. Top. Quantum Electron, 19 (4), 1100608 (2013).

28. Newell, T. C. et al. \& L. F. Lester. Gain and Linewidth Enhancement Factorin InAs Quantum-Dot Laser Diodes. IEEE Photonics Technol. Lett, 11, 12 (1999).

29. Wang, R., Tong, C. Z., Yoon, S. F., Liu, C. Y. \& Zhao, H. X. \& Q. Cao. Temperature characteristics of gain profiles in 1.3- $\mu \mathrm{m}$ p-doped andundoped InAs/GaAs quantum-dot lasers. IEEE Electron. Device Lett, 30 (12), 1311-1313 (2009).

30. Qiao, Z. L. et al. \&C. Y. Liu. High-performance 1.06- $\mu \mathrm{m}$ InGaAs/GaAs double-quantum-well semiconductor lasers with asymmetric heterostructure layers. Semicond. Sci. Technol, 34 (5), 055013 (2019).

31. Liu, C. Y. \& Stubenrauch, M. \& D. Bimberg. Spontaneous emission study on $1.3 \mu \mathrm{m} \ln A s / \ln G a A s / G a A s$ quantum dot lasers. Nanotechnology, 22, 235202 (2011). 
Figures

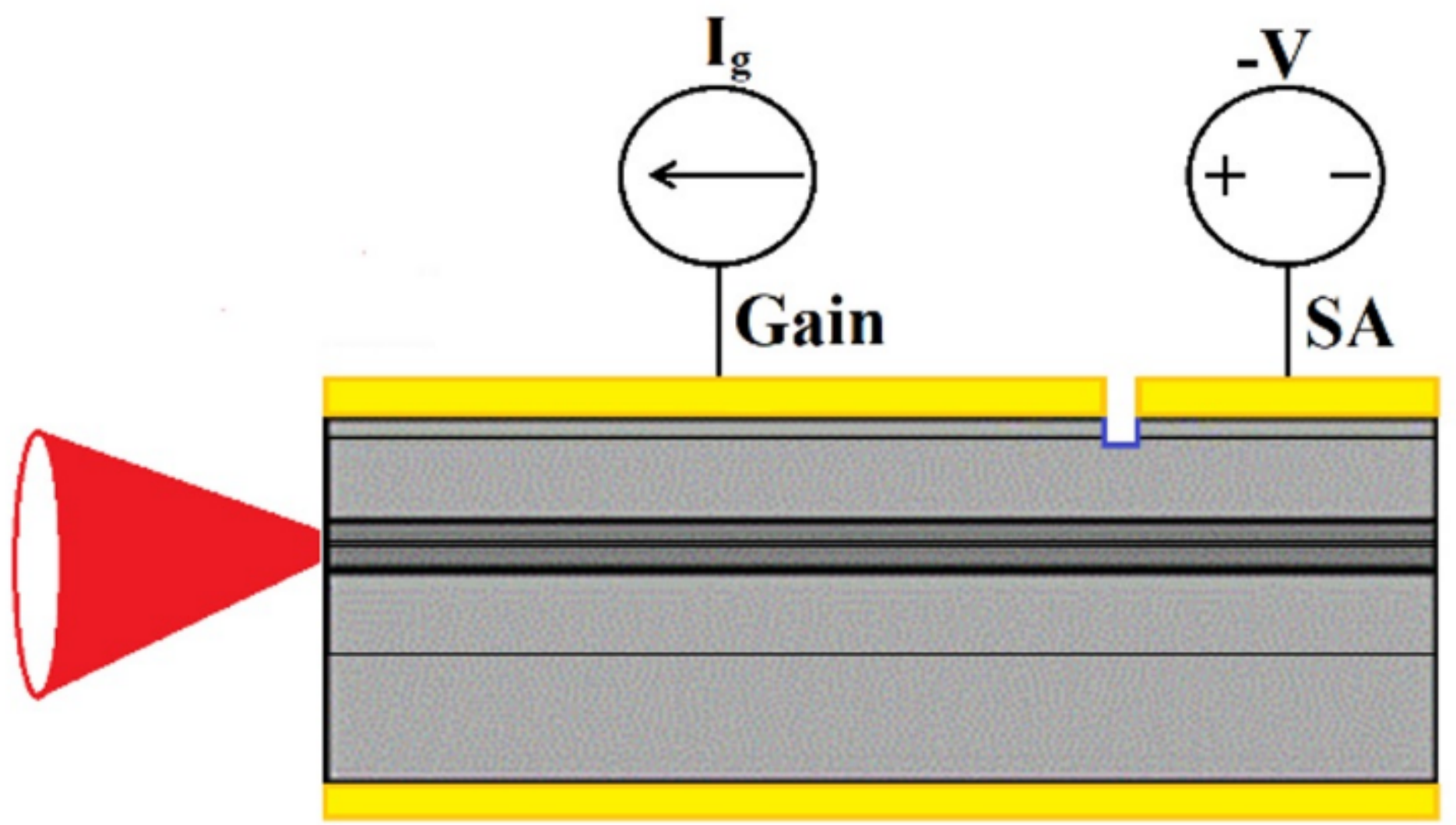

Figure 1

Sketch (side view) of the two-section MLL.

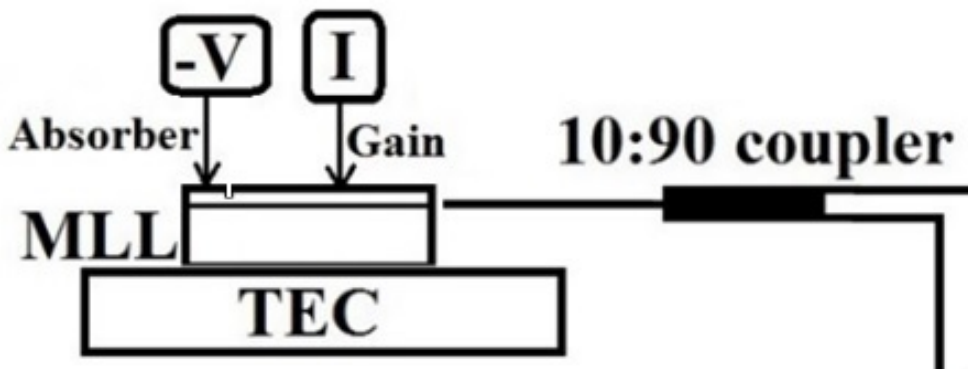

50:50 coupler

PD-ESA

PD- Oscilloscope

Figure 2

Schematic diagram of the MLL measurement setup 


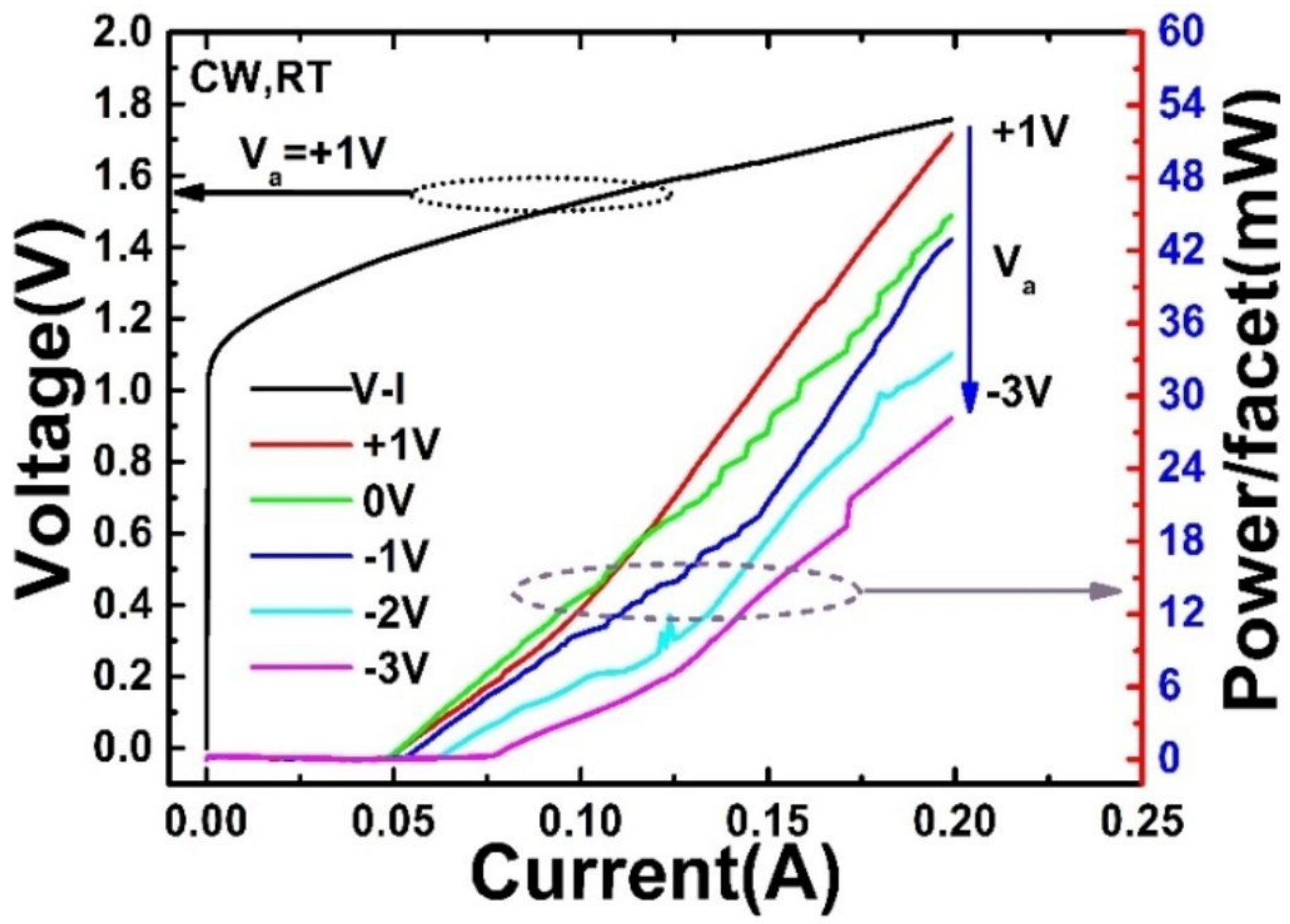

Figure 3

$\mathrm{L}-\mathrm{I}$ and $\mathrm{V}-\mathrm{I}$ curves of the laser with the absorber section bias ( $\mathrm{Va}$ ) varied from +1 to $-3 \mathrm{~V}$ at room temperature. 

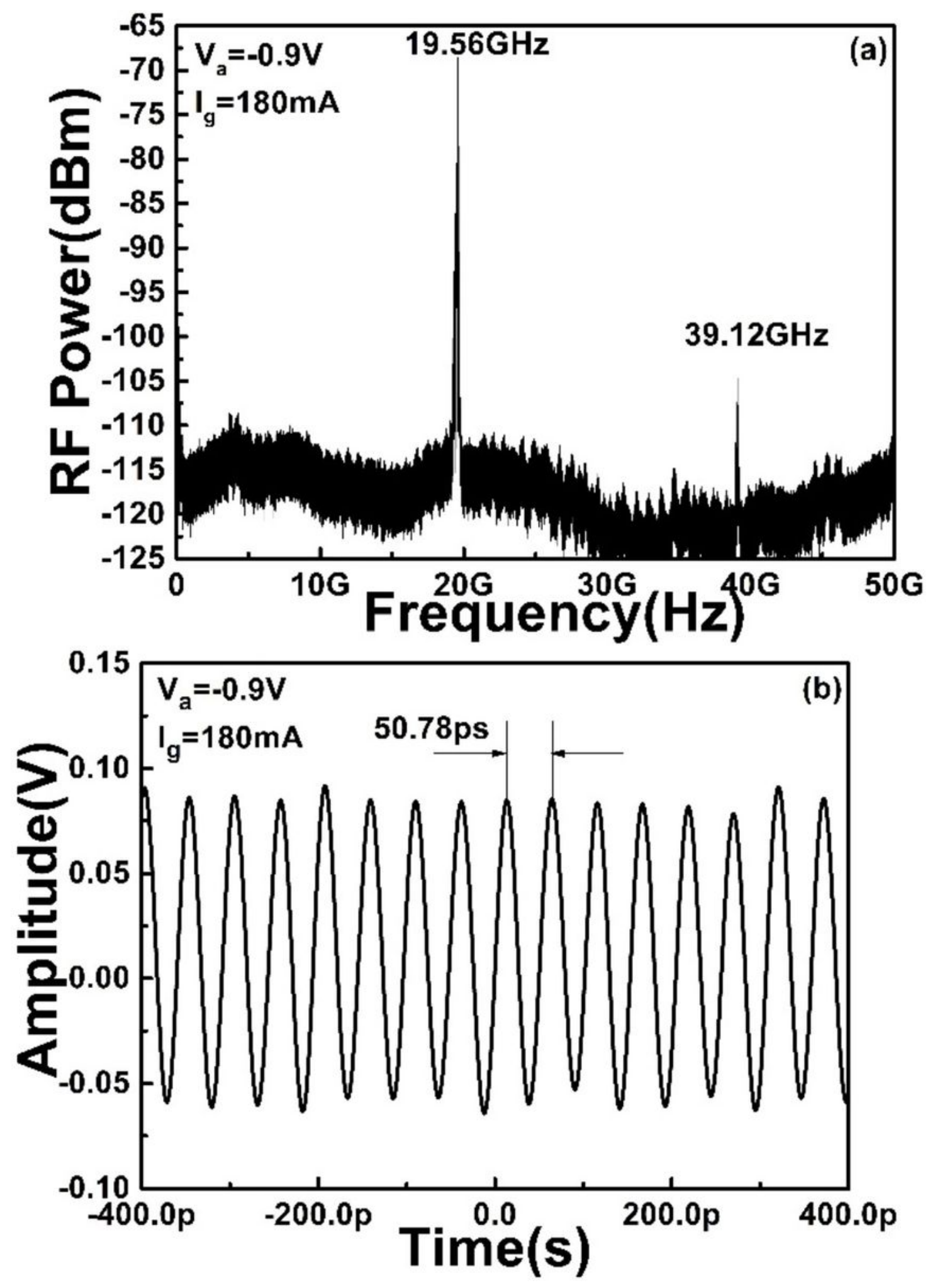

Figure 4

(a) Frequency spectrum of the MLL under the bias condition $(\mathrm{Ig}=180 \mathrm{~mA}, \mathrm{Va}=-0.9 \mathrm{~V})$. (b) pulse trains under the same bias condition. 


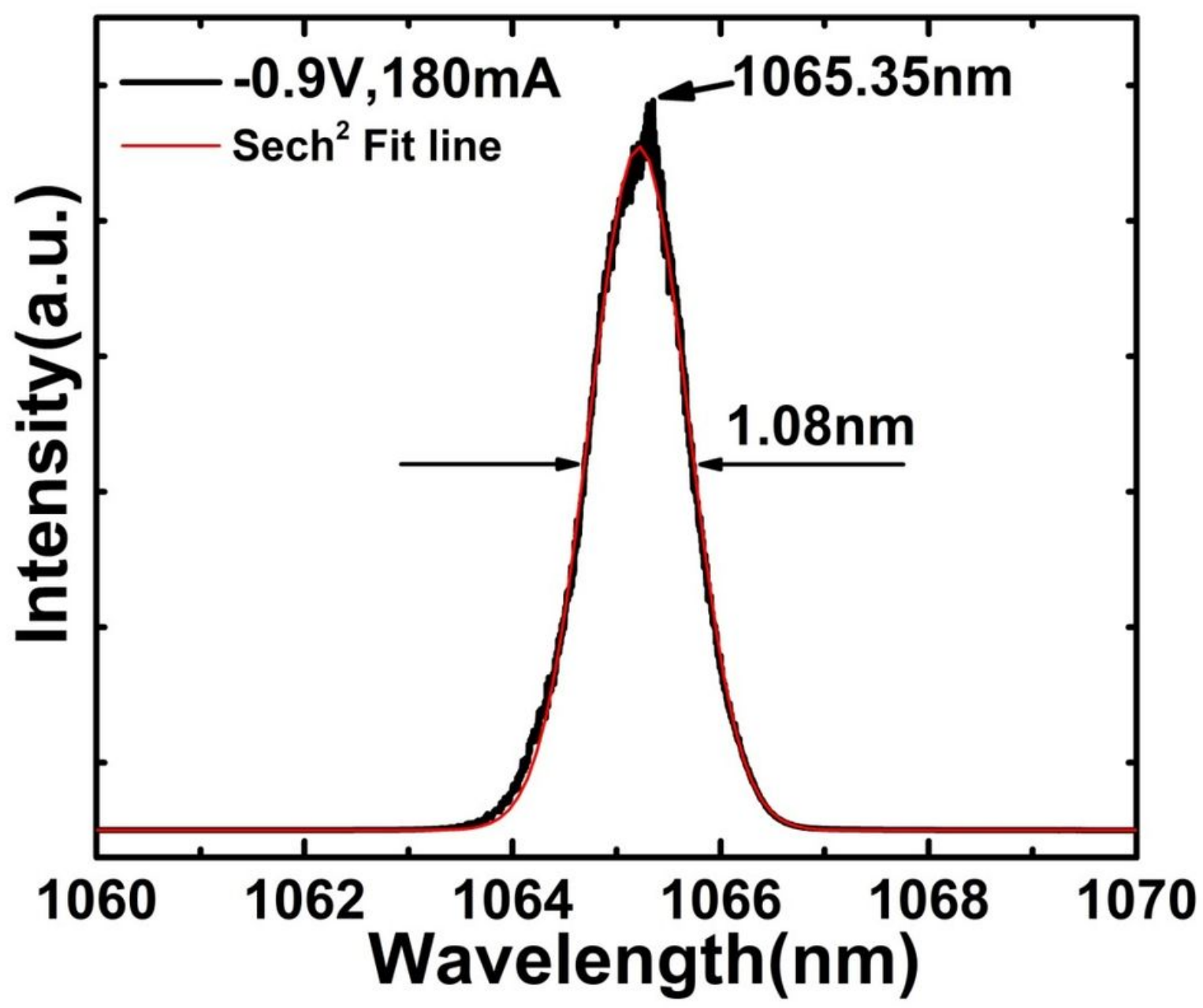

Figure 5

Spectrum of the MLLs when $P W=1.1 p s$. 

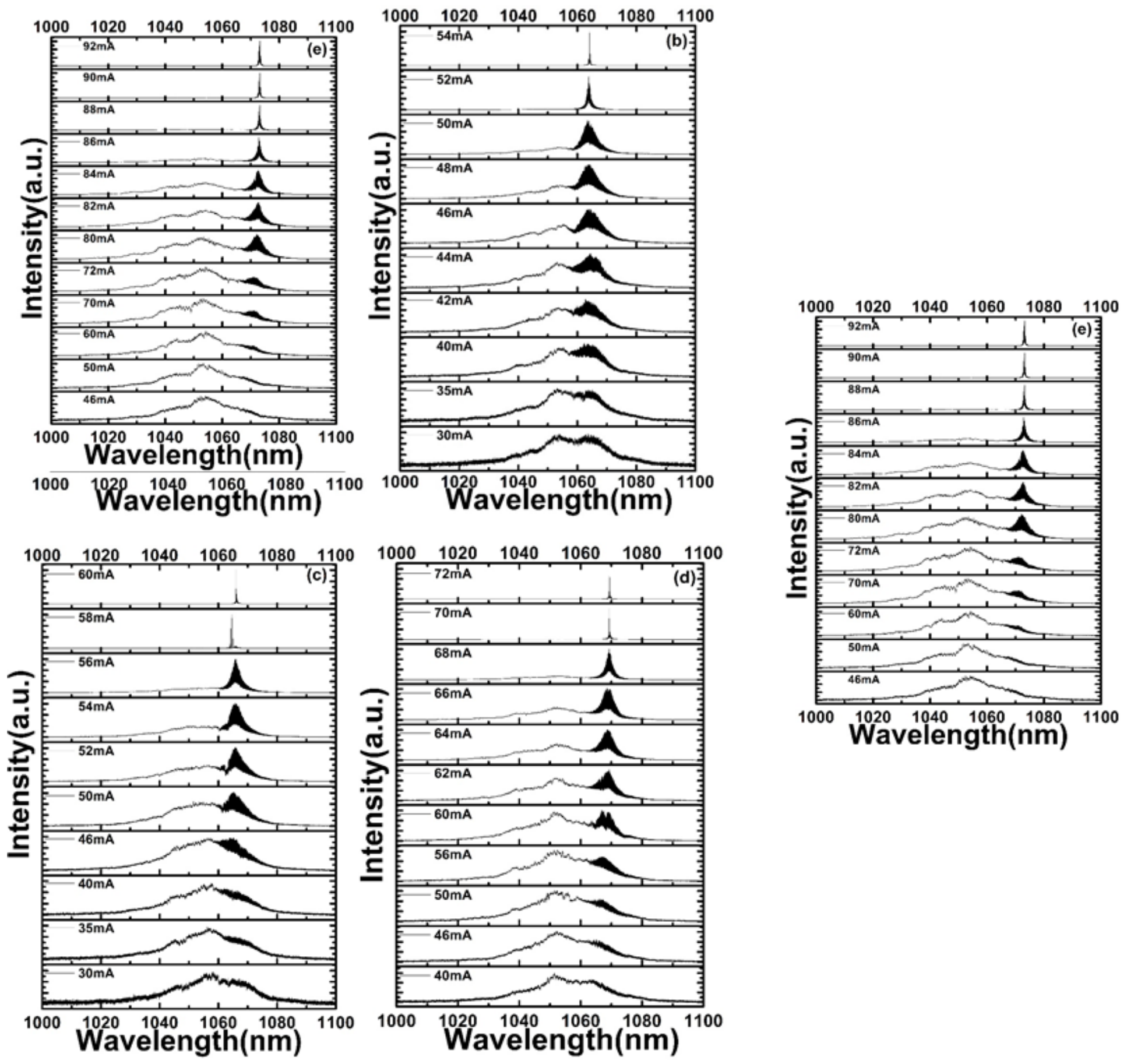

Figure 6

The spectra measured from the InGaAs/GaAs DQW MLL at different $\mathrm{Va}(\mathrm{a}: \mathrm{Va}=+1 \mathrm{~V} ; \mathrm{b}: \mathrm{Va}=0 \mathrm{~V}$; $\mathrm{c}: \mathrm{Va}=-1 \mathrm{~V}$ ; d: $V a=-2 V ; e: V a=-3 V)$. 

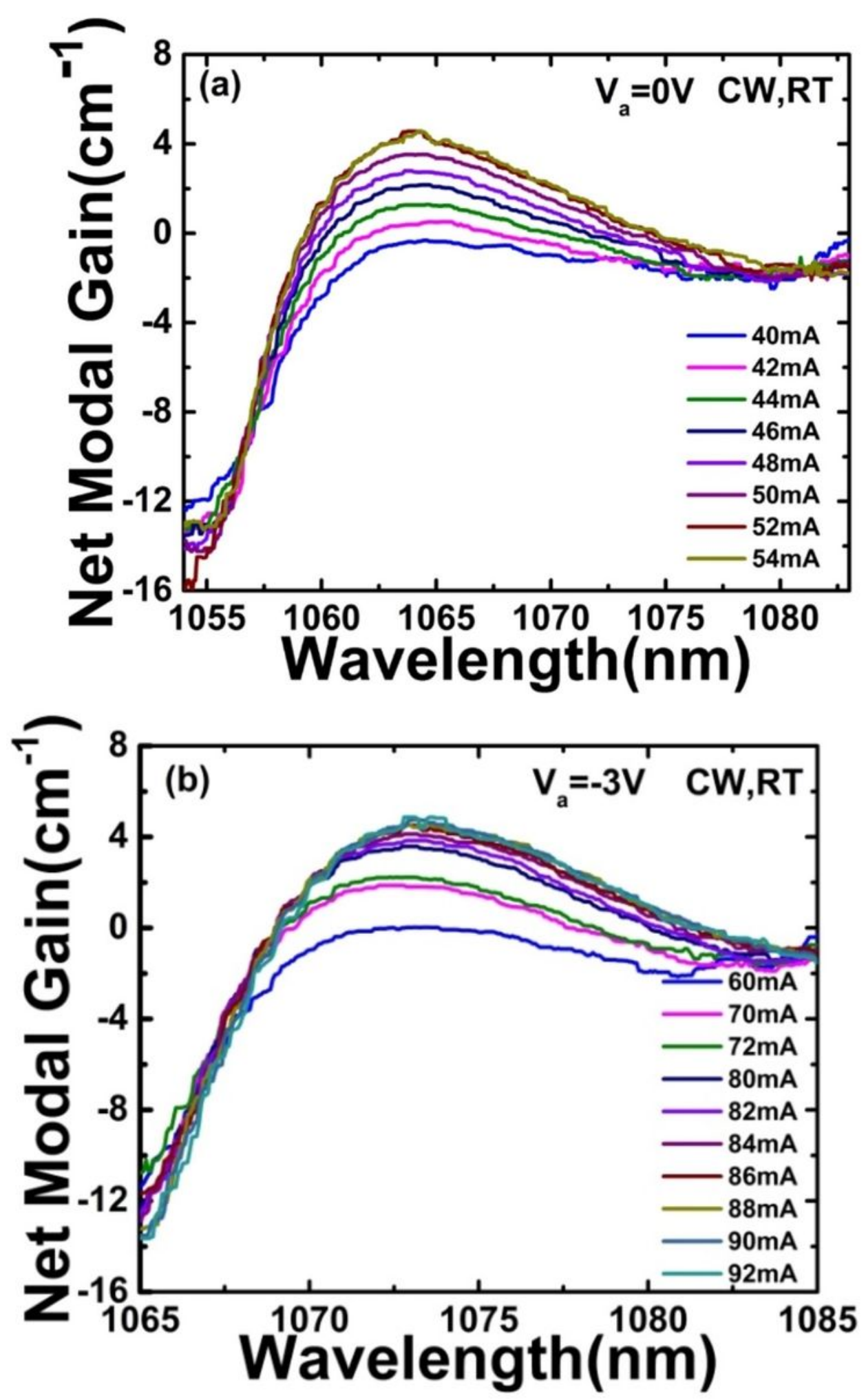

Figure 7

Net modal gain spectra of InGaAs/GaAs DQW lasers at bias $\mathrm{Va}(\mathrm{a}: \mathrm{Va}=0 \mathrm{~V} ; \mathrm{b}: \mathrm{Va}=-3 \mathrm{~V})$ 


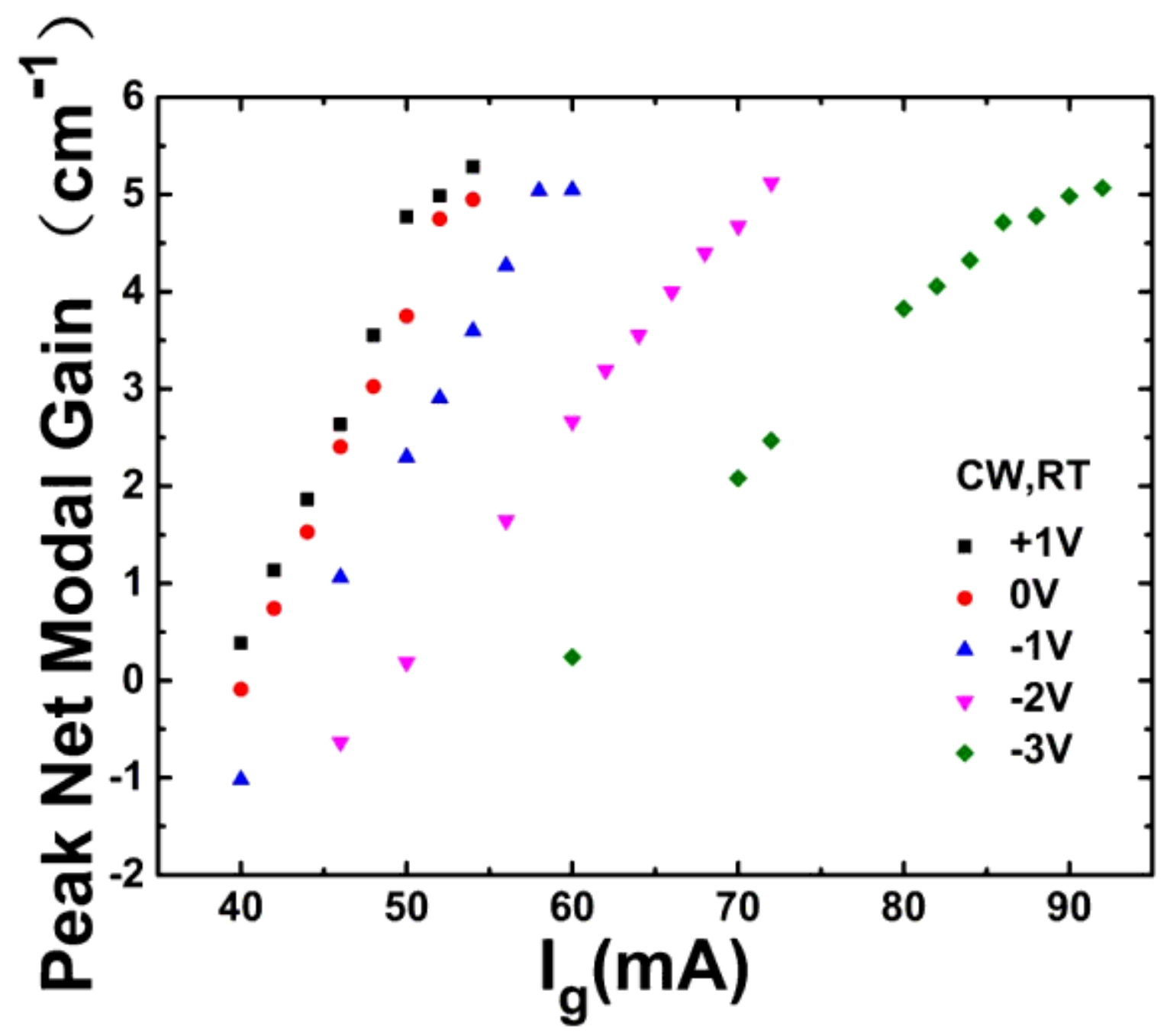

Figure 8

Peak net modal gain versus gain section current under $t+1 \mathrm{~V}, 0 \mathrm{~V},-1 \mathrm{~V},-2 \mathrm{~V}$, and $-3 \mathrm{~V}$, respectively. 

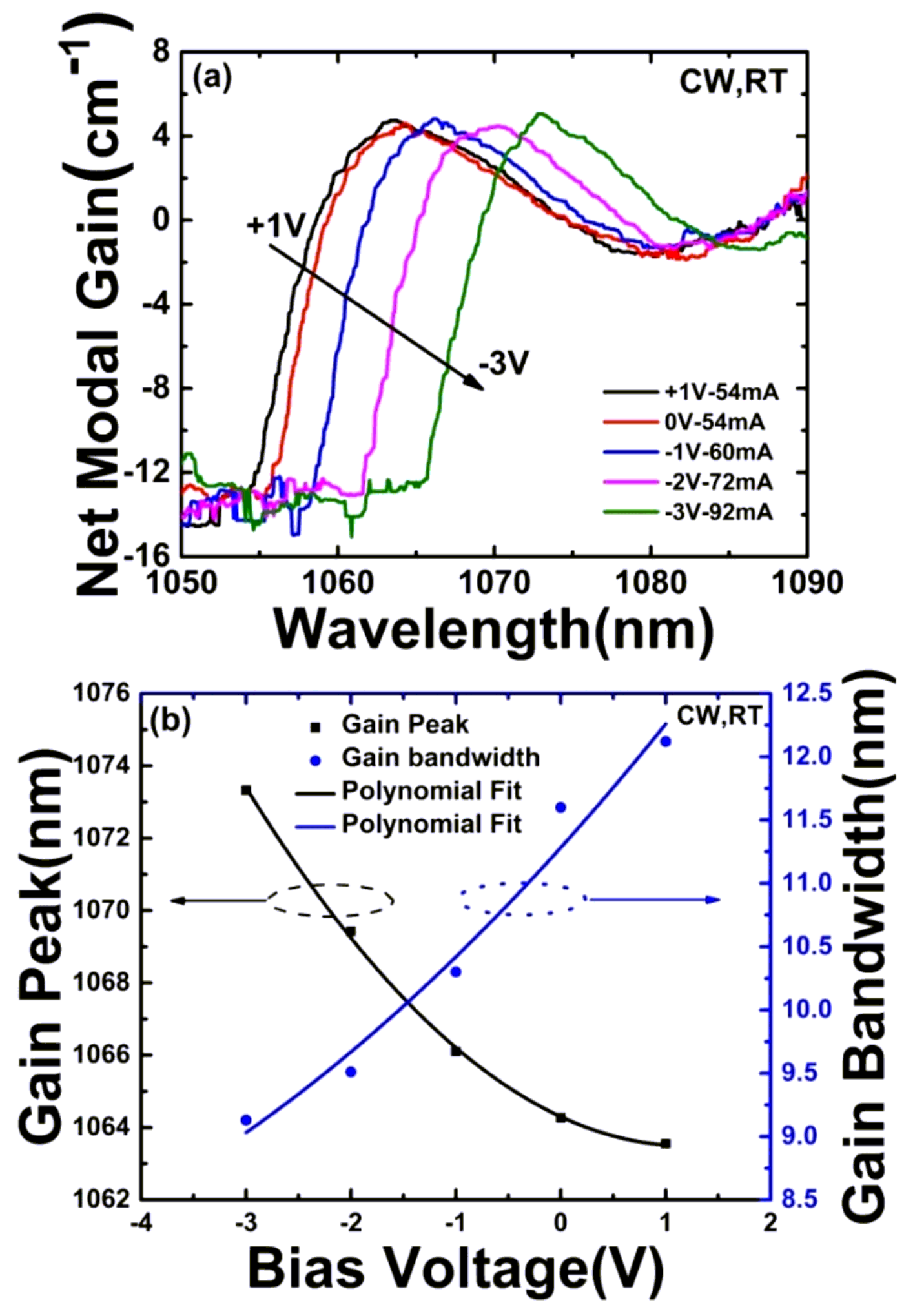

Figure 9

(a) Va-dependent threshold gain spectra of the MLL from +1 to $-3 \mathrm{~V}$. (b)Net modal gain bandwidth (Black square and polynomial fitting line) and peak net gain (blue circle and polynomial fitting line) of the MLL versus bias voltage, respectively. 


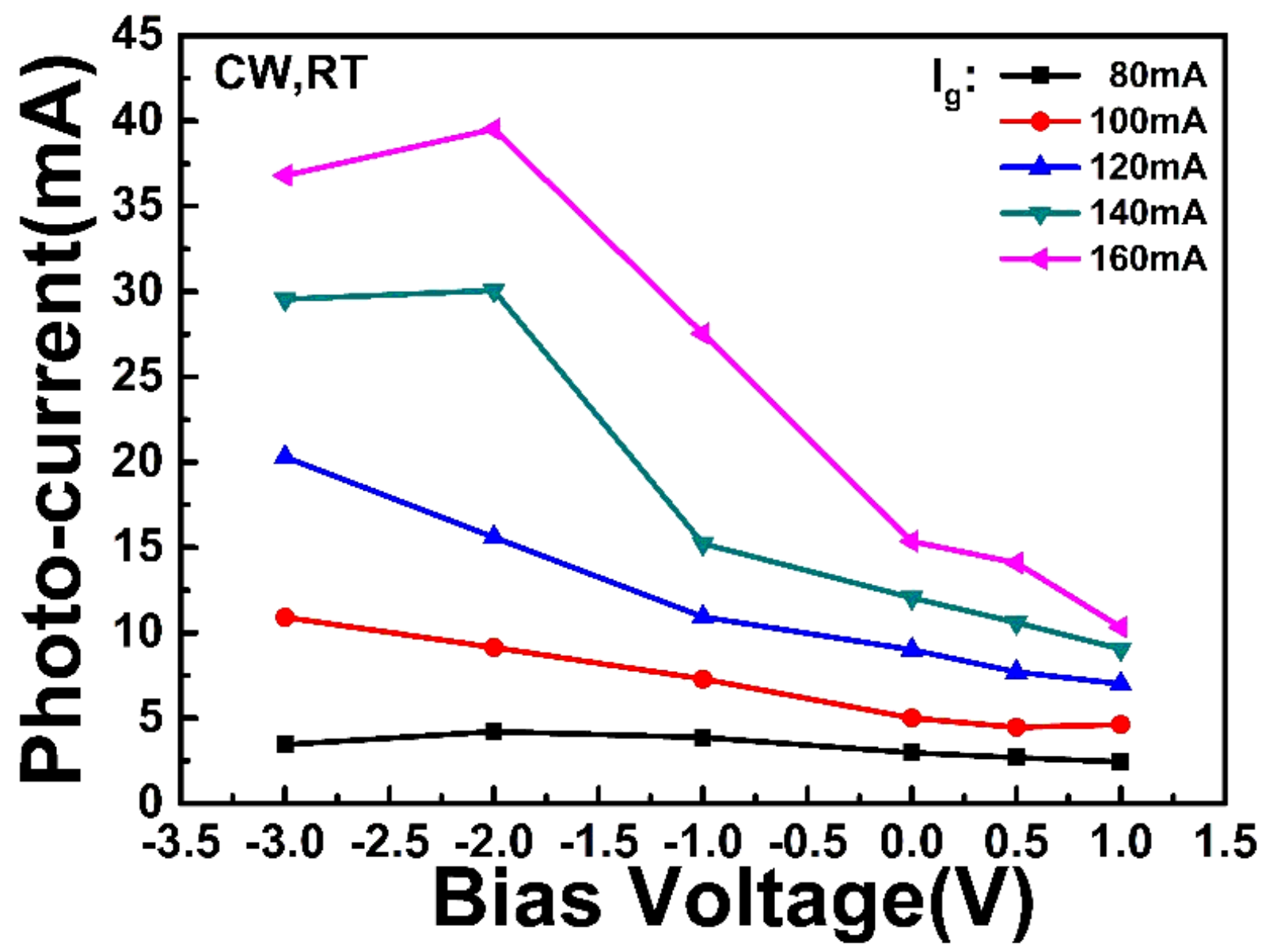

Figure 10

Photocurrent versus bias voltage under different lg. 